\title{
Genetic Variation of Local Varieties of Soybean in the Western Part of the Shikoku Mountains in Japan
}

\author{
Nguyen Van Huan, Hideki Sugimoto and Ko Harada* \\ Faculty of Agriculture, Ehime University, 3-5-7 Tarumi, Matsuyama, Ehime 790-8566, Japan
}

\begin{abstract}
Fifty-four accessions of local soybean strains collected from villages in the western part of the Shikoku Mountains were examined to assess genetic variation using the RAPD method. The accessions included 25 yellow, 17 black, 2 brown and 10 green seed-coat strains. Sixty-eight out of 138 bands detected by 21 RAPD primers were polymorphic. The average genetic distance for all the pairwise combinations was $0.114 \pm$ 0.0336 , which indicates that the local strains retained more than $80 \%$ of the genetic variation of the Japanese landraces reported previously. The genetic distance within yellow strains, black strains (including two brown strains) and green strains was $0.114 \pm 0.0273,0.0969 \pm 0.0333$ and $0.0840 \pm 0.0309$, respectively. These values were significantly different from each other. The genetic distance between the strains in groups with different seed-coat colors was significantly different from zero. The coefficient of genetic differentiation, $G_{\mathrm{ST}}$, among the seed-coat colors was 0.174 , indicating a large genetic differentiation. The $\mathrm{NJ}$ tree revealed the presence of three clusters: two were mainly composed of yellow and black strains, respectively, and the other one consisted of a mixture of yellow, black and green strains. However, monophyly of the seed-coat color groups was not supported except for some small subgroups. These results suggest that repeated introduction of seeds from outside seed sources and/or frequent hybridization among the strains with different seed-coat colors within the region had occurred during the long history of soybean cultivation in the Shikoku Mountains.
\end{abstract}

Key Words: local varieties, RAPD, shifting cultivation, Shikoku Mountains, soybean genetic variation.

\section{Introduction}

Shikoku Island is one of the regions where shifting cultivation had been carried out most intensively in Japan until the 1960's (Sasaki 1972). Many kinds of crops have been cultivated in this region, especially in mountainous areas called the Shikoku Mountains. Soma (1962) characterized the shifting cultivation practiced in the Shikoku Mountains and classified it into several types depending on the seasonal rotation system and the crops used. Among those crops, soybean (Glycine max (L.) Merr.) is one of the oldest and the most commonly used crops. Many local varieties of soybean have been developed in these areas. These varieties are expected to harbor combinations of genes conferring to the plants resistance to pests and diseases and genes favorable for growth and yield that have been accumulated under natural and artificial selections for adaptation to the local environments. The seeds of the crop have been carried by farmers when they moved and settled in new villages or by women who moved out when they married in other villages. Local varieties are thus important as a cultural heritage transmitted from generation to generation over a long time of period and as genetic resources. In order to preserve these varieties, it is

Communicated by O. Ohnishi

Received April 15, 2005. Accepted September 6, 2005.

*Corresponding author (e-mail: kharada@agr.ehime-u.ac.jp) important to determine the extent of the genetic variation harbored in the gene pool and phylogenetic relationships among the soybean strains.

Many kinds of molecular genetic markers have been recently developed and used to investigate genetic variation accumulated in the germplasm pool in both cultivated and wild soybeans. Among them, RAPD (Williams et al. 1990) is a simple technique which has been widely used to detect genetic variation in many crops, including soybeans, at the genomic level (Mienie et al. 1995, Thompson et al. 1998, Brown-Guedira et al. 2000, Li and Nelson 2001, 2002, Xu and Gai 2003, Chen and Nelson 2004). We collected soybean seeds from villages in mountainous areas of Shikoku, especially in the western part where shifting cultivation had been carried out intensively in the past, and examined the genetic variation of these samples using the RAPD method.

\section{Materials and Methods}

\section{Sample collection}

Soybean seed samples were collected from farmers who had cultivated soybean in villages in mountanious areas of Ehime and Kochi Prefectures on Shikoku Island. The collection sites are listed in Table 1 and shown in Figure 1. A total of 54 strains (each sample was considered to be a strain) were collected from 37 locations. The 54 strains included four different seed-coat color types: 25 strains with a yellow 
Table 1. Sampling location of local strains of soybean in the Shikoku Mountains

\begin{tabular}{|c|c|c|c|c|c|c|}
\hline No. & Location & Prefecture & Longitude & Latitude & Altitude (m) & Strains ${ }^{1)}$ \\
\hline 1 & Nishitani & Ehime & $33^{\circ} 41^{\prime} 13.4^{\prime \prime}$ & $133^{\circ} 04^{\prime} 29.8^{\prime \prime}$ & 696 & B11 \\
\hline 2 & Nakamura & Ehime & $33^{\circ} 40^{\prime} 20.8^{\prime \prime}$ & $133^{\circ} 04^{\prime} 06.4^{\prime \prime}$ & 592 & B10, G1 \\
\hline 3 & Kanmon & Ehime & $33^{\circ} 42^{\prime} 25.5^{\prime \prime}$ & $133^{\circ} 05^{\prime} 39.8^{\prime \prime}$ & 666 & B9, G2 \\
\hline 4 & Umegaichi & Ehime & $33^{\circ} 44^{\prime} 18.6^{\prime \prime}$ & $133^{\circ} 02^{\prime} 26.3^{\prime \prime}$ & 762 & B12 \\
\hline 5 & Koami & Ehime & $33^{\circ} 44^{\prime} 34.1^{\prime \prime}$ & $133^{\circ} 00^{\prime} 14.8^{\prime \prime}$ & 893 & Y19, B8, G3 \\
\hline 6 & Sawatari & Ehime & $33^{\circ} 36^{\prime} 27.8^{\prime \prime}$ & $132^{\circ} 59^{\prime} 36.5^{\prime \prime}$ & 632 & Y23, B15 \\
\hline 7 & Nagasaki & Ehime & $33^{\circ} 36^{\prime} 09.0^{\prime \prime}$ & $133^{\circ} 02^{\prime} 15.2^{\prime \prime}$ & 772 & $\mathrm{Y} 20$ \\
\hline 8 & Kurofujigawa & Ehime & $33^{\circ} 34^{\prime} 27.5^{\prime \prime}$ & $133^{\circ} 00^{\prime} 33.1^{\prime \prime}$ & 404 & B18 \\
\hline 9 & Oodochi & Ehime & $33^{\circ} 35^{\prime} 13.0^{\prime \prime}$ & $132^{\circ} 55^{\prime} 02.8^{\prime \prime}$ & 988 & B13 \\
\hline 10 & Ookawa & Ehime & $33^{\circ} 36^{\prime} 28.9^{\prime \prime}$ & $132^{\circ} 56^{\prime} 07.9^{\prime \prime}$ & 472 & B14 \\
\hline 11 & Nishimoto & Ehime & $33^{\circ} 33^{\prime} 02.7^{\prime \prime}$ & $133^{\circ} 02^{\prime} 15.2^{\prime \prime}$ & 676 & $\mathrm{Y} 21$ \\
\hline 12 & Nishitani & Ehime & $33^{\circ} 31^{\prime} 15.9^{\prime \prime}$ & $132^{\circ} 57^{\prime} 37.3^{\prime \prime}$ & 781 & Y24 \\
\hline 13 & Nakajyo & Ehime & $33^{\circ} 38^{\prime} 21.3^{\prime \prime}$ & $132^{\circ} 51^{\prime} 12.6^{\prime \prime}$ & 558 & Y22, G4 \\
\hline 14 & Nakagumi & Ehime & $33^{\circ} 41^{\prime} 51.6^{\prime \prime}$ & $132^{\circ} 57^{\prime} 52.6^{\prime \prime}$ & 536 & B16, B17, G5 \\
\hline 15 & Uriuno & Ehime & $33^{\circ} 51^{\prime} 29.8^{\prime \prime}$ & $132^{\circ} 25^{\prime} 26.9^{\prime \prime}$ & 822 & $\mathrm{Y} 25^{*}$ \\
\hline 16 & Sinotani & Ehime & $33^{\circ} 39^{\prime} 44.1^{\prime \prime}$ & $132^{\circ} 48^{\prime} 40.3^{\prime \prime}$ & 546 & Y6 \\
\hline 17 & Nakanokawa & Ehime & $33^{\circ} 38^{\prime} 55.7^{\prime \prime}$ & $132^{\circ} 46^{\prime} 44.5^{\prime \prime}$ & 533 & Y4 \\
\hline 18 & Takaichi & Ehime & $33^{\circ} 37^{\prime} 28.9^{\prime \prime}$ & $132^{\circ} 46^{\prime} 14.7^{\prime \prime}$ & 534 & Y5 \\
\hline 19 & Tateishi & Ehime & $33^{\circ} 33^{\prime} 33.5^{\prime \prime}$ & $132^{\circ} 45^{\prime} 50.1^{\prime \prime}$ & 229 & $\mathrm{Y} 11, \mathrm{~B} 1, \mathrm{~B} 2 *, \mathrm{G} 6$ \\
\hline 20 & Hujii & Ehime & $33^{\circ} 34^{\prime} 16.3^{\prime \prime}$ & $132^{\circ} 50^{\prime} 20.3^{\prime \prime}$ & 310 & $\mathrm{Y} 12, \mathrm{~B} 3$ \\
\hline 21 & Kitahira & Ehime & $33^{\circ} 30^{\prime} 48.3^{\prime \prime}$ & $132^{\circ} 48^{\prime} 04.6^{\prime \prime}$ & 451 & Y9 \\
\hline 22 & Uematu & Ehime & $33^{\circ} 28^{\prime} 52.7^{\prime \prime}$ & $132^{\circ} 44^{\prime} 21.0^{\prime \prime}$ & 380 & G7 \\
\hline 23 & Sougawa & Ehime & $33^{\circ} 28^{\prime} 11.4^{\prime \prime}$ & $132^{\circ} 47^{\prime} 41.5^{\prime \prime}$ & 695 & Y1 \\
\hline 24 & Inaya & Ehime & $33^{\circ} 28^{\prime} 10.0^{\prime \prime}$ & $132^{\circ} 47^{\prime} 08.7^{\prime \prime}$ & 359 & Y3 \\
\hline 25 & Yamato & Ehime & $33^{\circ} 28^{\prime} 54.8^{\prime \prime}$ & $132^{\circ} 49^{\prime} 30.1^{\prime \prime}$ & 686 & Y10 \\
\hline 26 & Kagio & Ehime & $33^{\circ} 23^{\prime} 32.1^{\prime \prime}$ & $132^{\circ} 44^{\prime} 35.9^{\prime \prime}$ & 205 & Y15 \\
\hline 27 & Yusudani & Ehime & $33^{\circ} 25^{\prime} 39.6^{\prime \prime}$ & $132^{\circ} 45^{\prime} 37.9^{\prime \prime}$ & 351 & Y7, B7 \\
\hline 28 & Izumi & Kochi & $33^{\circ} 29^{\prime} 43.7^{\prime \prime}$ & $133^{\circ} 06^{\prime} 11.0^{\prime \prime}$ & 572 & Y8*, B5 \\
\hline 29 & Matubara & Kochi & $33^{\circ} 30^{\prime} 08.4^{\prime \prime}$ & $133^{\circ} 03^{\prime} 02.4^{\prime \prime}$ & 754 & G8* \\
\hline 30 & Kuchimegaichi & Kochi & $33^{\circ} 27^{\prime} 06.6^{\prime \prime}$ & $133^{\circ} 01^{\prime} 51.2^{\prime \prime}$ & 701 & Y14, B4 \\
\hline 31 & Ootado & Kochi & $33^{\circ} 26^{\prime} 27.9^{\prime \prime}$ & $132^{\circ} 58^{\prime} 42.4^{\prime \prime}$ & 679 & Y16, G9 \\
\hline 32 & Inotani & Kochi & $33^{\circ} 26^{\prime} 56.0^{\prime \prime}$ & $132^{\circ} 57^{\prime} 24.0^{\prime \prime}$ & 832 & Y13 \\
\hline 33 & Simanaka & Kochi & $33^{\circ} 18^{\prime} 16.3^{\prime \prime}$ & $132^{\circ} 58^{\prime} 46.3^{\prime \prime}$ & 362 & Y18 \\
\hline 34 & Kochimuki & Kochi & $33^{\circ} 25^{\prime} 28.8^{\prime \prime}$ & $132^{\circ} 53^{\prime} 20.7^{\prime \prime}$ & 669 & B19, G10 \\
\hline 35 & Simotui & Kochi & $33^{\circ} 17^{\prime} 22.1^{\prime \prime}$ & $132^{\circ} 56^{\prime} 00.6^{\prime \prime}$ & 330 & $\mathrm{Y} 2 *$ \\
\hline 36 & Utuigawa & Kochi & $33^{\circ} 08^{\prime} 53.0^{\prime \prime}$ & $133^{\circ} 03^{\prime} 19.2^{\prime \prime}$ & 341 & B6 \\
\hline 37 & Nonokawa & Kochi & $33^{\circ} 11^{\prime} 01.8^{\prime \prime}$ & $132^{\circ} 54^{\prime} 22.1^{\prime \prime}$ & 524 & Y17 \\
\hline
\end{tabular}

1) The strains with Y, B and G prefixes refer to strains with yellow, black and green seed-coats, respectively. Strains with asterisks are strains with small grains.

coat, 17 with a black coat, 10 with a green coat and two with a brown coat. They were kept in a refrigerator at $4^{\circ} \mathrm{C}$ until use.

\section{DNA extraction}

Seeds were sown in paper cups and germinated in an incubator at $25^{\circ} \mathrm{C}$. Fresh young leaves were collected from a two weeks old plant for each strain. Total genomic DNA was extracted from these leaves using the CTAB method described by Doyle and Doyle (1990) with some modifications.

\section{Amplification of DNA}

A total of 63 RAPD primers (Operon, USA), including 20 primers of series A (OPA01-20), 20 of series B (OPB01$20), 18$ primers of series $\mathrm{C}$ (OPC $01-18), 2$ primers of series
D (OPD02 and OPD16), 2 primers of series E (OPE01 and OPE14) and 1 primer of series $\mathrm{F}$ (OPF10), were examined.

The polymerase chain reaction was carried out on a Gene Amp PCR system 9700. The reaction mixtures contained 10X PCR buffer, $2 \mathrm{mM}$ dNTP, 0.5 unit of taq DNA polymerase (Sigma, St. Louis, MO, USA), 5 pmol of primer and $5 \mathrm{ng}$ of template DNA in a total volume of $12.5 \mu \mathrm{l}$. The amplification program for RAPD was as follows: one first cycle of $95^{\circ} \mathrm{C}$ for 2 minutes followed by 40 cycles of $94^{\circ} \mathrm{C}$ for 1 minute, $40^{\circ} \mathrm{C}$ for 1 minute, and $72^{\circ} \mathrm{C}$ for 2 minutes, and holding at $72^{\circ} \mathrm{C}$ for 5 minutes. The amplification products were electrophoresed on $2 \%$ agarose gels with $1 \times \mathrm{TAE}(0.04$ $\mathrm{M}$ Tris-acetate and $1 \mathrm{mM}$ EDTA, $\mathrm{pH}$ 7.6). The gels were stained with ethidium bromide and photographed under UV light. 


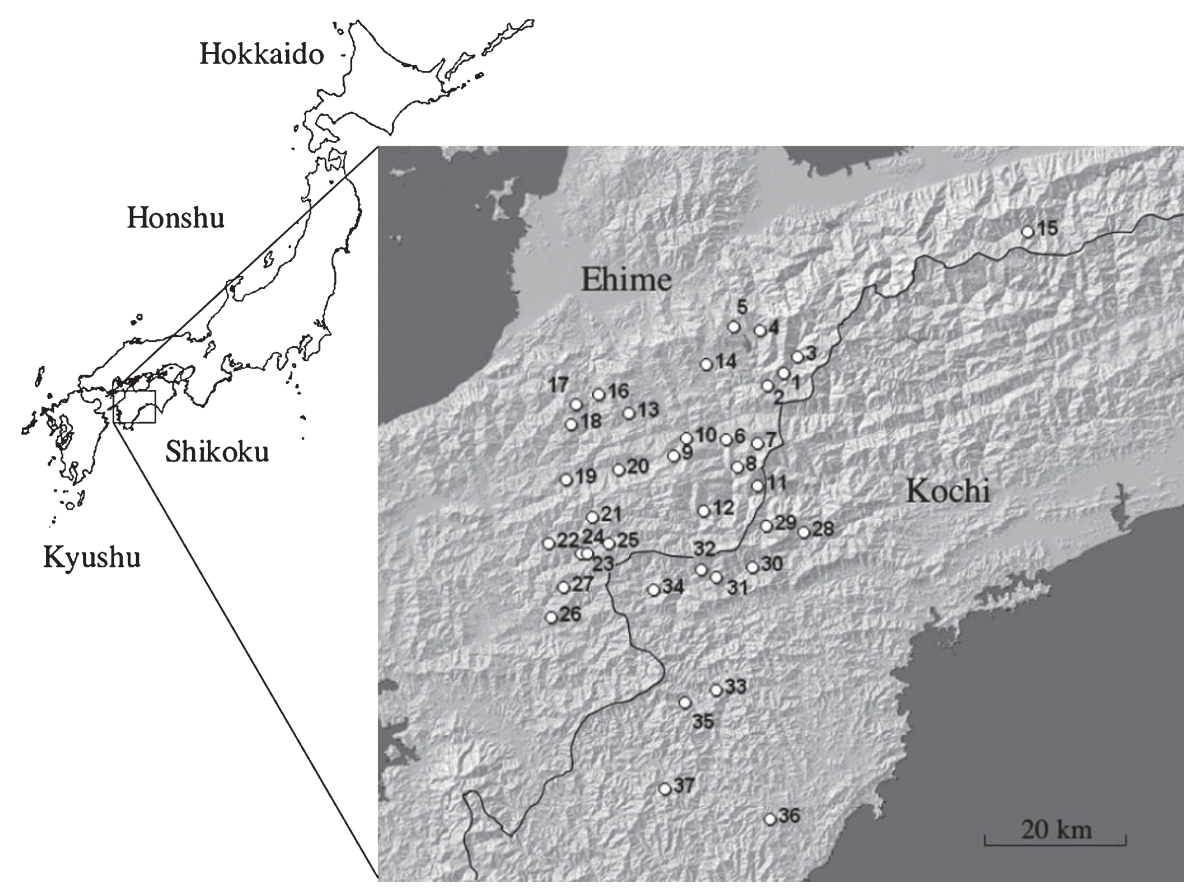

Fig. 1. Collection sites of local varieties of soybean in the Shikoku Mountains. Numbers in the figure correspond to the location numbers in Table 1.

\section{Data analysis}

The primers that yielded polymorphic bands were checked for stability in repeated reactions and only those that showed reproducible bands were selected for analysis. Here, the bands which showed a different status (presence or absence) at least in one individual in a group were considered to be polymorphic. A $0-1$ matrix was built by scoring 1 for the presence and 0 for the absence of bands. A matrix of pairwise distance was generated using PAUP4.0b10 (Swofford 2002), where mismatching $(1,0$ or 0,1$)$ tallied 1 and matching $(0,0$ or 1,1$)$ tallied 0 for each band locus and was averaged over all the loci between genotypes. The genetic distance is equal to one minus the similarity index of Nei and Li (1979). A phylogenetic tree was constructed by the neighbor-joining method (Saitou and Nei 1987) using the same software based on the distance matrix. Bootstrap values were calculated with 1000 replications.

Gene diversity for each locus was obtained by the formula $H_{i}=1-\Sigma p_{i j}^{2}$, where $p_{i j}$ is the frequency of the $j$ th allele at the $i$ th locus (Weir 1990). This value was averaged over all the loci to obtain the total gene diversity $(H)$. Allele frequencies were estimated assuming that the inbreeding coefficient $F=1$. This assumption may be valid because many field data have indicated that soybeans are normally autogamous with very limited outbreeding (Weber and Hanson 1961, Beard and Knowles 1971, Ahrent and Caviness 1994, and others). The coefficient of genetic differentiation $\left(G_{\mathrm{ST}}\right)$ among the seed coat color groups was estimated by the formula $G_{\mathrm{ST}}=\left(H_{\mathrm{T}}-H_{\mathrm{S}}\right) / H_{\mathrm{T}}$ (Nei 1973), where $H_{\mathrm{T}}$ and $H_{\mathrm{S}}$ are the gene diversities for overall and the average for the seed-coat color groups, respectively.

\section{Results}

A total of 63 primers produced a total of 387 bands for 54 local soybean strains. The number of bands detected from each primer ranged from one to sixteen bands, with an average of 6.1 bands/primer. The sizes of the fragments generated ranged from less than $300 \mathrm{bp}$ to approximately $3.0 \mathrm{~kb}$. Forty-two primers $(71.2 \%)$ gave polymorphic bands. Twentyone of them that produced clear and reproducible bands in repeated reactions were selected. These primers amplified a total of 138 bands, 68 (49.3\%) of which were polymorphic. The sizes of the polymorphic fragments ranged from approximately $300 \mathrm{bp}$ to $2700 \mathrm{bp}$ (Table 2 ).

The numbers of polymorphic bands for the strains with yellow, black and green seed-coats were 51 (37.0\%), 46 $(33.3 \%)$ and $32(23.2 \%)$, respectively, two brown strains (B11 and B15) being included in the black strains because brown strains are known to be the variants of black strains (Bernard and Weiss 1973). There were 24 bands that showed polymorphism for a specific seed-coat color group but not for others (11 such bands for yellow, 7 for black and 6 for green).

Genetic distances were calculated for pairwise combinations of all the strains. They ranged from 0.009 to 0.237 with an average value of $0.114 \pm 0.0336$. The average genetic distances within and between the seed-coat color groups were listed in Table 3. For the genetic distance within seedcoat color groups, yellow strains showed the largest genetic distance, while green strains the smallest. The difference between them was highly significant for all the comparisons $(\mathrm{P}<0.01$ by t-test). The genetic distance between groups with 
Table 2. Selected primers, oligonucleotide sequences and the size of polymorphic bands

\begin{tabular}{|c|c|c|}
\hline Primer & Sequence & Polymorphic band (bp) \\
\hline OPA-02 & 5'-TGCCGAGCTG-3' & $\begin{array}{l}300,380,420,500,780,810 \\
1080,1750,2300\end{array}$ \\
\hline OPA-06 & 5'-GGTCCCTGAC-3' & 2200 \\
\hline OPA-09 & 5'-GGGTAACGCC-3' & $610,660,710$ \\
\hline OPA-14 & 5'-TCTGTGCTGG-3' & $1150,1200,2300$ \\
\hline OPA-15 & 5'-TTCCGAACCC-3' & $\begin{array}{l}1000,1400,1700,1800,1900, \\
2200,2300\end{array}$ \\
\hline OPA-18 & 5'-AGGTGACCGT-3' & 480,680 \\
\hline OPA-20 & 5'-GTTGCGATCC-3' & $1200,1600,2000$ \\
\hline OPB-02 & 5'-TGATCCCTGG-3' & 1150 \\
\hline OPB-03 & 5'-CATCCCCCTG-3' & $\begin{array}{l}1150,1300,1700,1800,1900 \\
2100,2500\end{array}$ \\
\hline OPB-05 & 5'-TGCGCCCTTC-3' & $700,1500,2700$ \\
\hline OPB-06 & 5'-TGCTCTGCCC-3' & $850,1100,2500$ \\
\hline OPB-10 & 5'-CTGCTGGGAC-3' & 400 \\
\hline OPB-12 & 5'-CCTTGACGCA-3' & $650,850,950,1200,1450$ \\
\hline OPC-02 & 5'-GTGAGGCGTC-3' & $320,550,650,850$ \\
\hline OPC-04 & 5'-CCGCATCTAC-3' & 1550 \\
\hline OPC-06 & 5'-GAACGGACTC-3' & 1450 \\
\hline OPC-07 & 5'-GTCCCGACGA-3' & $500,600,760,820,1200$ \\
\hline OPC-15 & 5'-GACGGATCAG-3' & 320 \\
\hline OPC-16 & 5'-CACACTCCAG-3' & 870,1520 \\
\hline OPC-19 & 5'-GTTGCCAGCC-3' & 500 \\
\hline OPD-16 & 5'-AGGGCGTAAG-3' & $300,500,600,1100,1400$ \\
\hline
\end{tabular}

Table3. Average genetic distance within and between groups with different seed-coat colors. Standard deviations are shown in the parentheses.

\begin{tabular}{cccc}
\hline \hline Strains ${ }^{1)}$ & Yellow & Black & Green \\
\hline Yellow (25) & 0.114 & 0.125 & 0.118 \\
& $(0.0273)$ & $(0.0345)$ & $(0.0293)$ \\
Black (19) & & 0.0969 & 0.103 \\
& & $(0.0333)$ & $(0.0320)$ \\
Green (10) & & & 0.0840 \\
& & & $(0.0309)$ \\
\hline
\end{tabular}

1) Numbers in the parentheses indicate the number of strains used.

different seed-coat colors was significantly different from zero (at $1 \%$ level), showing considerable differentiation between the seed-coat color groups. Gene diversities with standard deviations were estimated to be $0.109 \pm 0.202$ for the yellow, $0.0917 \pm 0.149$ for the black and $0.0756 \pm 0.144$ for the green strains, and the overall diversity was $0.112 \pm 0.153$. The coefficient of genetic differentiation, $G_{\mathrm{ST}}$, among the groups was 0.174 , indicating the presence of a large genetic differentiation among the groups. The $G_{\mathrm{ST}}$ values between yellow and black, yellow and green, and black and green seed-coat groups were $0.115,0.159$ and 0.118 , respectively. The largest genetic differentiation was observed between the yellow and green seed-coat groups, confirming the results of genetic distance.

Three clusters (I, II and III) were recognized in the phylogenetic tree (Fig. 2) although the bootstrap values were low. Cluster I was mainly composed of yellow strains. It in-

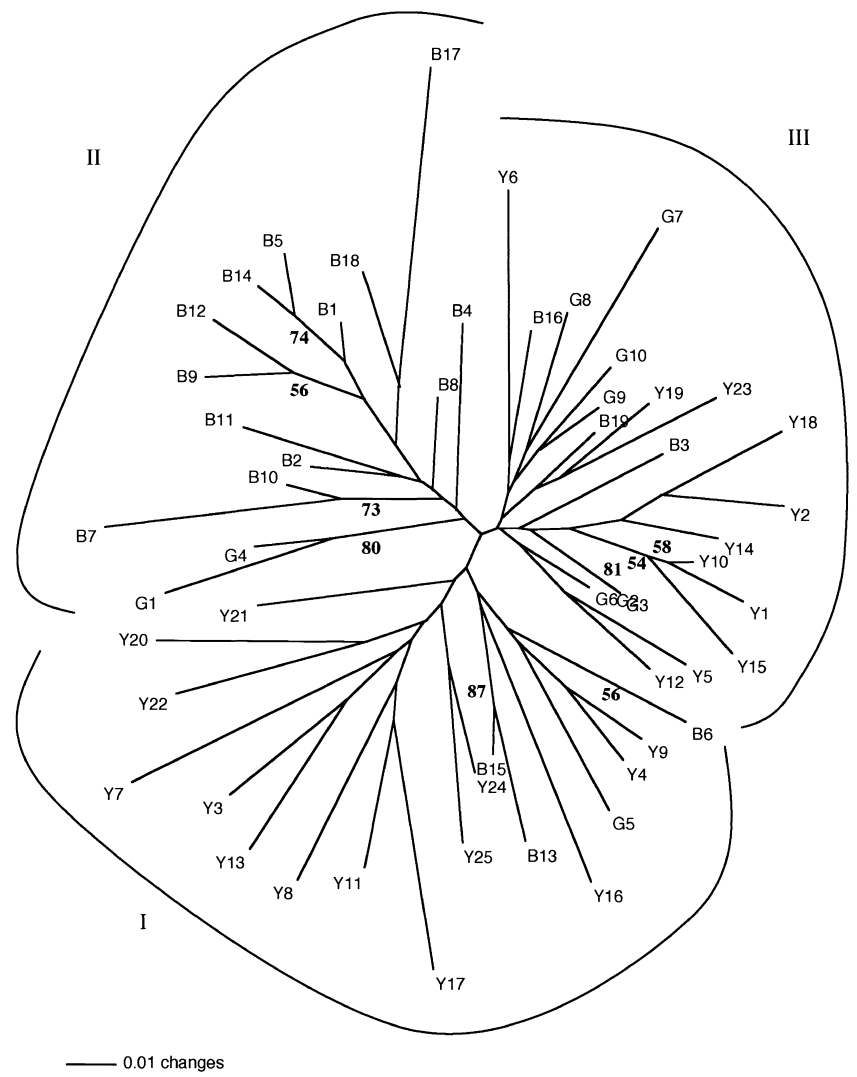

Fig. 2. Phylogenetic tree constructed by the NJ method based on genetic distance from pairwise comparison of RAPD bands between strains. Bootstrap values more than $50 \%$ are shown.

cluded 14 yellow, three black and one green strains. Cluster II was mainly composed of black strains. It included 13 black and two closely related green strains (G1 and G4). Cluster III was a mixture of strains with three seed-coat colors, containing 11 yellow, 3 black and 7 green strains. It should be noted that seven of the ten green strains were included in Cluster III. Medium to high bootstrap values $(>50 \%)$ were recorded only in seven of the outer branches connecting the strains with the same seed-coat color.

\section{Discussion}

Although RAPD is a simple and economical method, variability in RAPD profiles on the gel among different laboratory conditions has been reported. Since this is mainly due to the use of different PCR machines and different polymerases, it is, therefore, essential to maintain consistent reaction conditions in order to obtain reproducible results (Jones et al. 1997). In our experience, reproducibility could be achieved to a satisfactory level under carefully managed laboratory conditions. Despite the differences in the laboratory conditions and the different criteria used for selecting PCR primers, it may still be useful to compare the present results with those of previous studies to assess the level of genetic variation harbored in local strains in the Shikoku Mountains. Li and Nelson (2002), who used 37 selected 
RAPD primers, reported $64 \%$ of polymorphic bands in 40 cultivated soybean, G. max and 40 wild soybean, G. soja, accessions from four Chinese provinces. Genetic distance between the accessions was 0.160 for $G$. $\max$ and 0.212 for $G$. soja, showing a larger variation in the wild soybean accessions. Using 35 RAPD markers, Li et al. (2001) examined 32 landraces representing three major soybean-producing regions in the northeastern, central and southern parts of China and 18 North American soybean ancestral lines. The ancestral lines are lines from which more than $85 \%$ of modern US soybean cultivars have been derived. Polymorphism was $56 \%$ and the genetic distances were 0.174 for the US ancestral lines and 0.184 for the Chinese landraces. The distance between the Chinese landraces and US ancestral lines was 0.188. Li and Nelson (2001) examined 120 accessions from the USDA germplasm collection originating from eight Chinese and three South Korean provinces and from three Japanese districts using 35 RAPD primers. Only landraces were selected. They found the largest genetic distance within the Chinese accessions, 0.176, whereas the distance was almost the same, 0.137, within the S. Korean and within the Japanese accessions. Interestingly, their principal component analysis of RAPD fragments showed that the Japanese and Korean accessions were grouped together and separated from the Chinese accessions. Although the values recorded in this study is smaller than that obtained in previous studies for the accessions representing worldwide or nationwide markets of soybean strains, they are still considerably large. Consequently, assuming the presence of differences in primer sets and sampling bias, it was estimated that local strains cultivated in the western part of Shikoku retained $82 \%$ of the genetic variation of the Japanese cultivars reported by Li and Nelson (2001).

In our accessions, the largest variation in both genetic distance and gene diversity was observed within the yellow seed-coat group. Large genetic differentiation among the groups was also observed in the genetic distance and the coefficient of gene differentiation, $G_{\mathrm{ST}}$, between the groups. Seed-coat color is the most apparent and important criterion for classifying the strains because the utilization of soybeans in Japan depends on color types. Japanese traditional foods such as soybean curd (tofu), soybean paste (miso) and soy sauce (shoyu) are made of yellow strains. It is assumed that the smaller genetic variation shown in both black and green strains was caused by the reduced population size due to the limited use of these strains. Phylogenetic grouping in the NJ tree (Fig. 2) is mainly performed according to the seed-coat color of strains. Clusters I and II were mainly composed of yellow and black strains, respectively, and Cluster III consisted of a mixture of yellow, black and green strains. All the groupings with bootstrap values of more than $50 \%$ occurred on the branches with strains showing the same seed-coat color. The green seed-coat color is controlled by a single dominant gene, $G$, that retains chlorophyll in the seed coat at maturity (Nagai 1921, Woodworth 1921, Bernard and Weiss 1973), while the black seed-coat color is controlled by a dominant $R$ gene pigmenting anthocyanin (Nagai 1921, Bernard and Weiss 1973). It was observed that each of the two brown strains (B11 and B15) was grouped with a black strain (B11 and B2, and B15 and B13). They were separated into different clusters, suggesting the independent occurrence of brown color mutations. Actually, the brown color has been reported to be controlled by $r$, recessive to $R$ (Nagai 1921, Bernard and Weiss 1973). The phylogenetic tree (Fig. 2) apparently showed that the seed-coat color groups were not monophyletic. This suggests multiple origins of the seed-coat color mutants; independent mutations, independent introductions and/or occasional hybridizations between strains with different seed-coat colors during the long history of cultivation. All the yellow strains showed a whitishbrown hilum (except Y25, a possible hybrid), although there was a variation in the intensity. All the black seeds showed a black hilum. Green seeds showed two hilum colors, brownish-black and grey. Four of the green strains (G1, G4, G9 and G10) showed a grey hilum, and the remaining six a brownish-black one. G9 and G10 were grouped together and branched from strains with a brownish-black hilum in Cluster III. G1 and G4 were also grouped together but occurred independently in Cluster II. A brownish-black hilum is considered to be a mutation of the $I$ gene, an inhibitor of pigmentation, to $i^{i}$ (Bernard and Weiss 1973). The phylogenetic tree also suggested multiple occurrences of hilum color changes.

There were no apparent relationships between the genetic distance and the geographic distribution of the strains. Some pairs of very closely related strains, such as B9 and B12 (with a genetic distance of 0.038), and G2 and G3 (with the smallest genetic distance of 0.008), were found in the same village, Omogo (old name). Y1 and Y10 with a genetic distance of 0.023 were found in the same village, Yanadani (old name). On the other hand, some closely related strains were found in remote locations. For example, B5 and B14 with a genetic distance of 0.023 were found in areas $20 \mathrm{~km}$ apart, and B1 and B14 with a genetic distance of 0.030 were found in areas $14.5 \mathrm{~km}$ apart. The strains introduced from outside or which occurred by mutations were dispersed around the villages in some cases, but remained in the areas where the ancestral strains had been introduced in other cases. It is likely that seed dispersal mediated by human activities and commercial exchanges in a limited area like Shikoku had caused this mixture.

In the present study, a considerably large genetic variation was observed in the local varieties of soybean in the Shikoku Mountains. The polyphyletic nature of the NJ tree for the seed-coat color groups may indicate the repeated introduction of soybean into the mountainous area from outer seed sources. Although settlement of people in the Shikoku Mountains has been traced back to the medieval period ( $11^{\text {th }}$ to the end of $16^{\text {th }}$ century) (Soma 1962), it remains to be determined when soybeans were included in shifting cultivation in Shikoku. Considering the early introduction of soybean into Japan (beginning of the Yayoi period, third 
century, BC, Hoshikawa 1980) and the richness of the genetic variation observed, it appears that the inclusion of soybeans in shifting cultivation in Shikoku had also occurred at a very early time.

\section{Acknowledgements}

This study was carried out for the partial fulfillment of a doctoral thesis by N. V. Huan. This work was supported in part by a Grant-in-Aid for Scientific Research from the Ministry of Education, Culture, Sports, Science and Technology, Japan (no. 16651115) and a research grant from Ehime University.

\section{Literature Cited}

Ahrent,D.K. and C.E.Caviness (1994) Natural cross-pollination of twelve soybean cultivars in Arkansas. Crop Sci. 34: 376-378.

Beard,B.H. and P.F.Knowles (1971) Frequency of cross-pollination of soybeans after seed irradiation. Crop Sci. 11: 489-492.

Bernard,R.L. and M.G.Weiss (1973) Qualitative genetics. In: "Soybeans: Improvement, Production, and Uses" Caldwell, B.E. (ed.), Agron. Monor. 16, ASA, Madison, Wisconsin. p. 117154.

Brown-Guedira, G.L., J.A.Thompson, R.L.Nelson and M.L.Warburton (2000) Evaluation of genetic diversity of soybean introductions and North American ancesters using RAPD and SSR markers. Crop Sci. 40: 815-823.

Chen,Y. and R.L.Nelson (2004) Genetic variation and relationships among cultivated, wild, and semiwild soybeans. Crop Sci. 44 316-325.

Doyle,J.J. and J.L.Doyle (1990) Isolation of plant DNA from fresh tissue. Focus 12: 13-15.

Hoshikawa,K. (1980) Edible Crops. Yokendo, Tokyo. 697 p (in Japanese).

Jones, C.J., K.J.Edwards, S.Castaglione, M.O.Winfield, F. Sale et al. (1997) Reproducibility testing of RAPD, AFLP and SSR markers in plants by a network of European laboratories. Mol. Breed. 3: 381-390.

Li,Z. and R.L.Nelson (2001) Genetic diversity among soybean accessions from three countries measured by RAPDs. Crop Sci. 41: 1337-1347.

Li,Z., L.Qiu, J.A.Thompson, M.M.Welsh and R.L.Nelson (2001) Mo- lecular genetic analysis of U. S. and Chinese soybean ancestral lines. Crop Sci. 41: 1330-1336.

Li,Z. and R.L.Nelson (2002) RAPD marker diversity among cultivated and wild soybean accessions from four Chinese provinces. Crop Sci. 42: 1737-1744.

Mienie,C.M.S., M.A.Smit and P.J.Pretorius (1995) Use of random amplified polymorphic DNA for identification of South African soybean cultivars. Field Crops Res. 43: 43-49.

Nagai,I. (1921) A genetico-physiological study on the formation of anthocyanin and brown pigments in plants. Tokyo Univ. Coll. Agr. J. 8: 1-92.

Nei,M. (1973) Analysis of gene diversity in subdivided populations. Proc. Natl. Acad. Sci. USA 70: 3321-3323.

Nei,M and W.-H.Li (1979) Mathematical model for studying genetic variation in terms of restriction endonucleases. Proc. Natl. Acad. Sci. USA 76: 5269-5273.

Saitou,N. and M.Nei (1987) The neighbor-joining method: A new method reconstructing phylogenetic trees. Mol. Biol. Evol. 4: 406-425.

Sasaki,K. (1972) Shifting Cultivation in Japan. Kokin Shoin, Tokyo. $457 \mathrm{p}$ (in Japanese).

Soma,M. (1962) The regional structure of shifting cultivation area in Shikoku Mountains. Ehime Daigaku Kiyo 4: 1-79 (in Japanese with English summary).

Swofford,D.L. (2002) PAUP*. Phylogenetic Analysis Using Parsimony (and Other Methods) 4.0 Beta. Sinauer Associates, Sunderland, MA.

Thompson,J.A., R.L.Nelson and L.O.Vodkin (1998) Identification of diverse soybean germplasm using RAPD markers. Crop Sci. 38: $1348-1355$.

Weber,C.R. and W.D.Hanson (1961) Natural hybridization with and without ionizing radiation in soybean. Crop Sci. 1: 389-392.

Weir,B.S. (1990) Genetic Data Analysis II. Sinauer Associates, Sunderland, Massachusetts. $443 \mathrm{p}$.

Williams, J.G.K., A.R.Kubelik, K.J.Livak, J.A.Rafalski and S.V. Tingey (1990) DNA polymorphism amplified by arbitrary primers are useful as genetic markers. Nuc. Acids Res. 18: 6531-6535.

Woodworth,C.M. (1921) Inheritance of cotyledon, seed-coat hilum, and pubescence colors in soy-beans. Genetics 6: 487-553.

Xu,D.H. and J.Y.Gai (2003) Genetic diversity of wild and cultivated soybeans growing in China revealed by RAPD analysis. Plant Breed. 122: 503-506. 